\title{
Molecular characterization of G-protein-coupled receptor (GPCR) and protein kinase A (PKA) CDNA in Perinereis aibuhitensis and expression during benzo(a)pyrene exposure
}

\author{
Huang Yi ${ }^{\text {Equal first author, } 1}$, Sun Jia ${ }^{\text {Equal first author, } 1}$, Han Ping ${ }^{1}$, Zhao Heling ${ }^{2}$, Wang Mengting ${ }^{1}$, Zhou Yibing $^{1}$, Yang Dazuo ${ }^{1}$, \\ Zhao Huan ${ }^{\text {Corresp. } 1}$ \\ ${ }^{1}$ Key Laboratory of Marine Bio-Resources Restoration and Habitat Reparation in Liaoning Province, Dalian Ocean University, Dalian, Liaoning, China \\ Asian Herpetological Research Editorial Office, Chengdu Institute of Biology, Chinese Academy of Sciences, Cheng du, Sichuan, China \\ Corresponding Author: Zhao Huan \\ Email address: zhaohuan@dlou.edu.cn
}

Background. G-protein-coupled receptors (GPCRs) are one of the most important molecules that transfer signals across the plasma membrane, and play central roles in physiological systems. The molecular architecture of GPCRs allows them to bind to diverse chemicals, including environmental contaminants.

Methods. To investigate the effects of benzo(a)pyrene (B[a]P) on GPCR signaling, GPCR and the protein kinase A (PKA) catalytic subunit of Perinereis aibuhitensis were cloned. The expression patterns of these two genes during $\mathrm{B}(\mathrm{a}) \mathrm{P}$ exposure were determined with real-time fluorescence quantitative PCR. The PKA content in $P$. aibuhitensis under $\mathrm{B}(\mathrm{a}) \mathrm{P}$ exposure was examined

Results. The full-length cDNAs of PaGPCR and the PaPKA catalytic subunit were 1,514 and 2,662 nucleotides, respectively, encoding 338 and 350 amino acids, respectively. Multiple sequence alignments indicated that the deduced amino acid sequence of PaGPCR shared a low level of similarity with the orphan GPCRs of polychaetes and echinoderms, whereas PaPKA shared a high level of identify with the PKA catalytic subunits of other invertebrates. B(a)P exposure time-dependently elevated the expression of PaGPCR and PaPKA. The expression of both PaGPCR and PaPKA was also dose-dependent, except at a dose of $10 \mu \mathrm{g} / \mathrm{L} \mathrm{B}(\mathrm{a}) \mathrm{P}$. The PKA content in concentration group was elevated on day 4 , with time prolonging the PKA content was down-regulated to control level.

Discussion. These results suggested that GPCR signaling in $P$. aibuhitensis was involved in the polychaete's response to environmental contaminants. 
2 Molecular characterization of G-protein-coupled receptor (GPCR) and protein

$3 \quad$ kinase A (PKA) cDNA in Perinereis aibuhitensis and expression during

7 Huang $\mathrm{Yi}^{1}$, Sun $\mathrm{Jia}^{1}$, Han Ping ${ }^{1}$, Zhao Heling ${ }^{2}$,Wang Mengting ${ }^{1}$, Zhou Yibing ${ }^{1}$, Yang Dazuo ${ }^{1}$, 8 Zhao Huan ${ }^{1}$

${ }^{1}$ Key Laboratory of Marine Bio-Resources Restoration and Habitat Reparation in Liaoning

12 Province, Dalian Ocean University, Dalian, Liaoning, China

$13{ }^{2}$ Asian Herpetological Research Editorial Office, Chengdu Institute of Biology, Chinese

14 Academy of Sciences, Chengdu, Sichuan, China

17 Corresponding Author:

Zhao Huan ${ }^{1}$

Shahekou District heroitte street no.52, Dalian, Liao ning, 116023, China

Email address: 15206936767@163.com

\section{Abstract}

23 Background. G-protein-coupled receptors (GPCRs) are one of the most important molecules

24 that transfer signals across the plasma membrane, and play central roles in physiological

25 systems. The molecular architecture of GPCRs allows them to bind to diverse chemicals, 26 including environmental contaminants. 
27 Methods. To investigate the effects of benzo(a)pyrene (B(a)P) on GPCR signaling, GPCR and

28

29

30

31

32

33

34

35

36

37

38

39

40

41

42

43

44

45

46

47

48

49

50

51

52

53

54

55

56

57

58

59

60

61

62

63

64

65

the protein kinase A (PKA) catalytic subunit of Perinereis aibuhitensis were cloned. The expression patterns of these two genes during $\mathrm{B}(\mathrm{a}) \mathrm{P}$ exposure were determined with real-time fluorescence quantitative PCR. The PKA content in P. aibuhitensis under B(a)P exposure was examined.

Results. The full-length cDNAs of $P a G P C R$ and the $P a P K A$ catalytic subunit were 1,514 and 2,662 nucleotides, respectively, encoding 338 and 350 amino acids, respectively. Multiple sequence alignments indicated that the deduced amino acid sequence of PaGPCR shared a low level of similarity with the orphan GPCRs of polychaetes and echinoderms, whereas PaPKA shared a high level of identify with the PKA catalytic subunits of other invertebrates. B(a)P exposure time-dependently elevated the expression of PaGPCR and PaPKA. The expression of both $P a G P C R$ and $P a P K A$ was also dose-dependent, except at a dose of $10 \mu \mathrm{g} / \mathrm{L}$ B(a)P. The PKA content in concentration group was elevated on day 4 , with time prolonging the PKA content was down-regulated to control level.

Discussion. These results suggested that GPCR signaling in $P$. aibuhitensis was involved in the polychaete's response to environmental contaminants.

\section{Introduction}

Benzo(a)pyrene (B(a)P), a kind of polycyclic aromatic hydrocarbon (PAH), can cause genetic damage, immune and endocrine dysfunction, and malformation in humans and other organisms. Its high lipophilicity allows it to absorb to organic matter and other particulate matter and thus accumulate in sediments. Recent increases in offshore oil production and transportation and the sewerage discharge of domestic and industrial wastewater have led to environmental pollution in coastal regions, and $\mathrm{B}(\mathrm{a}) \mathrm{P}$ has been widely detected in sediments around the world, even in China. The levels of B(a)P in the sediments of Dalian Bay vary from 10.5 to $3421.2 \mathrm{ng} / \mathrm{g}$ (Zhang, 2008), and in the sediments around the drilling platform in the Bohai Sea, the concentration of $\mathrm{B}$ (a)P is up to $27.69 \mathrm{ng} / \mathrm{g}$ (Yang et al, 2016). PAH such as B(a)P can be absorbed by benthic organisms via ingestion or through their body surfaces, and $\mathrm{B}(\mathrm{a}) \mathrm{P}$ is reported to have serious effects on deposit feeders. Therefore, the toxicity and bioavailability of B(a)P are important factors in the assessment of sediment pollution.

G-protein-coupled receptors (GPCRs) are the largest superfamily of cellmembrance proteins (Fredriksson et al, 2003). The molecular architecture of the GPCRs allows them to bind to diverse organic and inorganic molecules. GPCRs mediate cell proliferation and survival by transmitting signals from a range of extracellular ligands across the cell membrane to signaling pathways. In vertebrates, they are key regulators of the innate and adaptive immune responses and have been investigated as potential targets in drug discovery (Garland, 2013). However, examples of GPCRs in invertebrates are limited. Miller et al. (2015) reported that Caenorhabditis elegans with mutations in the GPCR follicle-stimulating hormone receptor 1 (FSHR-1) died significantly more quickly in the presence of cadmium than wild-type nematodes, which suggests that this GPCR pathway protects the nematode against cadmium-induced

Peer) reviewing PDF | (2019:07:38998:1:1:NEW 8 Oct 2019) 
66

67

68

69

70

71

72

73

74

75

76

77

78

79

80

81

82

83

84

85

86

87

88

89

90

91

92

93

94

95

96

97

98

99

100

101

102

103

104

damage. They also found that FSHR-1 antagonizes the capacity of C. elegans to resist cold stress, and the mutants lacking $f s h r-1$ survived better than wild-type worms at low temperatures. Dong and Zhang (2012) identified a putative GPCR gene, HPIR, in the red swamp crayfish Procambarus clarkia, and the expression of $H P I R$ was significantly increased in the presence of Gram-negative bacteria.

Because the aromatic structures present a number of GPCR ligands, GPCRs are potential targets of aromatic pollutants such as B(a)P (Ferrec and Ovrevik, 2018). Mayati et al. (2012) reported the interaction between $\mathrm{B}(\mathrm{a}) \mathrm{P}$ and the $\beta_{2}$-adrenergic receptor $\left(\beta_{2} \mathrm{ADR}\right)$ in endothelial HMEC-1 cells and the consequent increase in intracellular $\mathrm{Ca}^{2+}$, which influenced the expression of cytochrome P450 B1. This suggests that $\beta_{2} \mathrm{ADR}$, a kind of GPCRs, is potentially involved in the deleterious effects of B(a)P. Factor et al. (2011) also observed the reduced expression and function of $\beta_{2} \mathrm{ADR}$ in airway epithelial cells and smooth muscle cells after their exposure to a mixture of PAHs. This implies that the $\beta_{2} \mathrm{ADR}$ signal transduction pathway is affected by PAHs. These data indicate that PAHs, including B(a)P, modulate the concentrations of intracytosolic cyclic adenosine monophosphate (cAMP) or $\mathrm{Ca}^{2+}$ via G-protein-dependent mechanisms (Bainy, 2007; Nadal et al., 2000).

The marine polychaete Perinereis aibuhitensis is widely distributed in the mudflats and estuarine sediments that occur widely along the coasts of Southeast Asia. They spend most of their lives within the sediments, ensuring their continuous contact with any sediment-associated contaminants. Chen et al. (2012) identified a CYP4 gene of P. aibuhitensis and showed that exposure to petroleum hydrocarbons significantly induced the expression of this gene. To clarify whether GPCR signal transduction pathway was involved in modulating the toxicity of aromatic pollutants, the full-length GPCR and protein kinase A ( $P K A)$ cDNAs were cloned and the expression patterns of these two genes were determined in this study. Our results provide important information on the function of GPCRs in polychaetes.

\section{Materials \& Methods}

\section{B(a)P exposure}

Perinereis aibuhitensis specimens (10-15 cm, $2.0 \pm 0.5 \mathrm{~g}$ wet weight) were collected from Dalian Dongyuan aquaculture farm at the estuary of Jinzhou Bay in Dalian, China.we have a long term cooperation agreement with the farm. The agreement permits us to collect research samples from all their aquaculture sites including a certain estuary area under their ownership (The field permit is attached in supplemental files). The animals were transferred to the laboratory and acclimatized in filtered seawater (salinity $31-32$, temperature $16 \pm 0.5^{\circ} \mathrm{C}$ ) for a week before the experiment. During acclimatization, the $P$. aibuhitensis were fed a powdered mix containing kelp powder, gulf-weed powder, fish meal, yeast, and spirulina powder. The worms were deprived of food during their exposure to $\mathrm{B}(\mathrm{a}) \mathrm{P}$.

Based on the standard seawater quality of the People's Republic of China (GB 3097-1997), four B(a)P concentration groups were established: $0.5,5,10$, and $50 \mu \mathrm{g} / \mathrm{L}$. A blank (seawater only) group and an acetone control group $(100 \mu \mathrm{L} / \mathrm{L})$ were also established. Three repetitions of 
105

106

107

108

109

110

111

112

113

114

115

116

117

118

119

120

121

122

123

124

125

126

127

128

129

130

131

132

133

134

135

136

137

138

139

140

141

142

143

144

each concentration group were set up. Ten worms were randomly placed in $2 \mathrm{~L}$ beakers containing different concentrations of B(a)P. During the experiment, the temperature of the seawater was $16 \pm 0.5^{\circ} \mathrm{C}$, and the seawater was renewed every $24 \mathrm{~h}$. On days 4,7 , and 14 of the experiment, four individuals were randomly sampled from each concentration group, and the body wall was removed for gene expression analysis. Three individuals was randomly sampled for PKA content analysis.

\section{Cloning the full-length $G P C R$ and $P K A$ cDNAs of $P$. aibuhitensis}

Three worms in blank group were ground to powder and the total RNA was extracted with RNAiso $^{\text {TM }}$ Plus (TaKaRa, Dalian, China). The quality of the RNA was determined with 1\% agarose gel electrophoresis. The RNA (500 ng) was reverse transcribed to cDNA for the rapid amplification of cDNA ends (RACE) using the SMARTer® RACE Kit (Clontech, Palo Alto, CA, USA). The 3' and 5' RACE primers were designed with the Primer 5.0 software (PREMIER Biosoft, Palo Alto, CA, USA) according to the confirmed partial sequences of GPCR and PKA obtained from $P$. aibuhitensis transcriptome sequences in our laboratory (unpublished). The primers used in this study are shown in Table 1.

The 3' RACE amplification of P. aibuhitensis GPCR (PaGPCR) was performed using the 3' RACE cDNA as the template. The PCR system $(50 \mu \mathrm{L})$ for PaGPCR contained $15.5 \mu \mathrm{L}$ of PCRgrade water, $25.0 \mu \mathrm{L}$ of $2 \times$ SeqAmp Buffer, $1.0 \mu \mathrm{L}$ of SeqAmp DNA polymerase, $2.5 \mu \mathrm{L}$ of 3' RACE cDNA, $5.0 \mu \mathrm{L} 10 \times \mathrm{UPM}$ (universal primer mixture), and $1.0 \mu \mathrm{L}$ of primer GPCR-F1 (10 $\mu \mathrm{M})$. The thermal cycling conditions were: 35 cycles of denaturation at $94^{\circ} \mathrm{C}$ for $30 \mathrm{~s}$, annealing at $65^{\circ} \mathrm{C}$ for $30 \mathrm{~s}$, and extension at $72^{\circ} \mathrm{C}$ for $3 \mathrm{~min}$. The $3^{\prime} \mathrm{RACE}$ amplification of $P$. aibuhitensis $P K A(P a P K A)$ was performed with nested PCR. The outer PCR reaction system for $P a P K A$ was the same as that for $P a G P C R$, except that a specific primer was used. The reaction conditions for the outer PCR were: 35 cycles of denaturation at $94^{\circ} \mathrm{C}$ for $30 \mathrm{~s}$, annealing at $63.9^{\circ} \mathrm{C}$ for $30 \mathrm{~s}$, and extension at $72^{\circ} \mathrm{C}$ for $3 \mathrm{~min}$. The outer PCR product $(5.0 \mu \mathrm{L})$ was diluted with $245 \mu \mathrm{L}$ of TE buffer, and $5.0 \mu \mathrm{L}$ of the diluted product was used as the template for the inner PCR. The reaction conditions and system for the inner PCR were the same as for the outer PCR of PaPKA.

The 5' RACE product of $P a G P C R$ was amplified with nested PCR. The outer PCR reaction system $(50 \mu \mathrm{L})$ for $P a G P C R$ contained $15.5 \mu \mathrm{L}$ of PCR-grade water, $25.0 \mu \mathrm{L}$ of $2 \times$ SeqAmp Buffer, $1.0 \mu \mathrm{L}$ of SeqAmp DNA polymerase, $2.5 \mu \mathrm{L}$ of $5^{\prime}$ RACE cDNA, $5.0 \mu \mathrm{L}$ of $10 \times \mathrm{UPM}$, and $1.0 \mu \mathrm{L}$ of primer GPCR-R1 $(10 \mu \mathrm{M})$. The reaction conditions for the outer PCR were: 35 cycles of denaturation at $94^{\circ} \mathrm{C}$ for $30 \mathrm{~s}$, annealing at $60^{\circ} \mathrm{C}$ for $30 \mathrm{~s}$, and extension at $72^{\circ} \mathrm{C}$ for 3 min. The outer PCR product $(5.0 \mu \mathrm{L})$ of $P a G P C R$ was diluted with $245 \mu \mathrm{L}$ of TE buffer and 5.0 $\mu \mathrm{L}$ of the diluted product was used as the template for the inner PCR. The reaction system (50 $\mu \mathrm{L}$ ) for the inner PCR of PaGPCR contained $5.0 \mu \mathrm{L}$ of the diluted outer PCR product, $17.0 \mu \mathrm{L}$ of PCR-grade water, $25.0 \mu \mathrm{L}$ of $2 \times$ SeqAmp Buffer, $1.0 \mu \mathrm{L}$ of SeqAmp DNA Polymerase, $1.0 \mu \mathrm{L}$ of UPM Short, and $1.0 \mu \mathrm{L}$ of primer GPCR-R2 $(10 \mu \mathrm{M})$. The reaction conditions were: 20 cycles of denaturation at $94^{\circ} \mathrm{C}$ for $30 \mathrm{~s}$, annealing at $60^{\circ} \mathrm{C}$ for $30 \mathrm{~s}$, and extension at $72^{\circ} \mathrm{C}$ for $3 \mathrm{~min}$. The $5^{\prime}$ RACE of PaPKA was amplified with ordinary PCR, and the reaction system and conditions were the same as those for $P a G P C R$. 
The PCR products were detected with 1\% agarose gel electrophoresis and purified with the Agarose Gel DNA Purification Kit (Tiangen, Beijing, China), according to the manufacturer's instructions. The PCR products were sequenced by Takara Biotechnology Co. Ltd.

\section{Bioinformatic analysis of PaGPCR and PaPKA}

The amino acid sequences of $P a G P C R$ and $P a P K A$ were deduced with the Expert Protein Analysis System (http://www.us.expasy.org/tools). The conserved domain in each amino acid sequence was analyzed with the Motif Scan (http://www.hits.isbsib.ch/cgi-bin/PESCAN) and Expasy (http://www.au.expasy.org/prosite/). The protein localization sites in the cell were predicted with the Psort software (http://psort.hgc.jp/form2.html). The transmembrane (TM) helix in the protein were predicted with the TMHMM software (http://www.cbs.dtu.dk/services/TMHMM/). The tertiary structures of PaGPCR and PaPKA were predicted with the Swiss-Model software (http://swissmodel.expasy.org/interactive). Multiple sequences were aligned with the Clustal W software (http://www.ebi.ac.uk/clustalW). Phylogenetic analysis of GPCR and PKA were performed in MEGA 5.0. The tree topologies were evaluated with bootstrapping, using 1,000 replicates.

\section{Expression of PaGPCR and PaPKA genes during B(a)p exposure}

Real-time fluorescence quantitative PCR was used to investigate the expression of the two genes in $P$. aibuhitensis during $\mathrm{B}(\mathrm{a}) \mathrm{p}$ exposure. The $\beta$-actin gene was used as the reference gene, according to our previous study (Li et al., 2018). The primer information is shown in Table 1. Amplification was performed in $20 \mu \mathrm{L}$ reaction system containing $10 \mu \mathrm{L}$ of SYBR Premix Ex Taq II (Tli RNaseH Plus)(TaKaRa, Dalian, China), $0.8 \mu \mathrm{L}$ of each primer $(10 \mu \mathrm{M}), 0.4 \mu \mathrm{L}$ of $50 \times$ ROX Reference Dye II, $2.0 \mu \mathrm{L}$ of cDNA, and $6.0 \mu \mathrm{L}$ of $\mathrm{H}_{2} \mathrm{O}$. The reaction conditions were: $95^{\circ} \mathrm{C}$ for $30 \mathrm{~s}$, then 40 cycles of $95^{\circ} \mathrm{C}$ for $5 \mathrm{~s}$ and $60^{\circ} \mathrm{C}$ for $34 \mathrm{~s}$. The melting curves were analyzed after the real-time quantitative PCR. The standard curves were tested with serial 10fold sample dilutions. The slopes of the standard curves and the PCR efficiency were calculated to confirm the accuracy of the real-time PCR data.

\section{PKA content in $P$. aibuhitensis under B(a)P exposure}

Body wall (about $100 \mathrm{mg}$ ) of each sample was homogenized in $0.9 \mathrm{~mL}$ cold phosphate buffer saline (PBS) with pH 7.4. The homogenate was centrifuged at $4^{\circ} \mathrm{C}$ at $3000 \mathrm{rpm} / \mathrm{min}$ for $15 \mathrm{~min}$. The supernatants were assayed for PKA content using the non-radioactive PKA assay kit (Kexing, shanghai, China) with the method of ELISA according to manufacturer's protocol. Results are expressed as $\mathrm{ng} / \mathrm{mL}$.

\section{Statistical analysis}

The relative quantitative ( $2^{-\triangle \Delta \mathrm{Ct}}$ ) method was used to analyze the expression of the PaGPCR and $P a P K A$ genes. The data are expressed as means \pm standard deviations (SD), and one-way analysis of variance was used to analyze the significance of the differences among the different concentration groups at each sampling point, with the SPSS 19.0 software. $P$ values $\leq 0.05$ were considered statistically significant.

\section{Results}


184

185

186

187

188

189

190

191

192

193

194

195

196

197

198

199

200

201

202

203

204

205

206

207

208

209

210

211

212

213

214

215

216

217

218

219

220

221

222

223

\section{Molecular characterization of $P a G P C R$}

The 5'RACE and 3'RACE products of $P a G P C R$ was $1082 \mathrm{bp}$ and $800 \mathrm{bp}$, respectively (see supplemental file of PCR database ), and the full length cDNA of PaGPCR was obtained by sequence assembly. The full-length cDNA of $P a G P C R$ was $1,514 \mathrm{bp}$ and included a $5^{\prime}$ untranslated region (UTR) of $213 \mathrm{bp}$, a 3' UTR of $284 \mathrm{bp}$, and an open reading frame (ORF) of $1,017 \mathrm{bp}$, encoding 338 amino acids with a predicted molecular weight of $38.799 \mathrm{kDa}$ and a theoretical isoelectric point of 9.38 (Figure 1). This nucleotide sequence was deposited in the GenBank database under accession number KX792261. The seven-transmembrane (7TM)-helix bundle (304-1,146 bp) that defines the GPCR protein family was present in PaGPCR. The glutamic acid/aspartic acid-arginine-tyrosine (E/DRY) motif (amino acids 124-126) at the border between TM III and intracellular loop 2 and the NPXXY motif (amino acids 298-302) of TM VII near the inner cell membrance were detected in the deduced protein sequence, indicating that the protein sequence belonged to the rhodopsin family. In an amino acid comparison, PaGPCR shared 33\% similarity with the orphan GPCR of Platynereis dumerilii and $30 \%-33 \%$ similarity with galanin receptor type 2 of echinoderms (Figure 2).

The predicted cellular localization of the PaGPCR protein showed it mostly located on the cell membrane (52.2\%), and seven TM helices were predicted in the deduced protein sequence (Figure 3). The three-dimensional structural analysis of PaGPCR showed that it contained seven $\alpha$-helices, similar to the GPCRs of other animals (Figure 4). Its three-dimensional structure and protein localization confirmed that this protein sequence was a GPCR.

\section{Molecular characterization of $\mathrm{PaPKA}$}

The 5'RACE and 3'RACE products of PaPKA was $1918 \mathrm{bp}$ and $1765 \mathrm{bp}$, respectively (see supplemental file of PCR database ), and the full length cDNA of PaPKA was obtained by sequence assembly. The total length of $P a P K A$ cDNA was $2662 \mathrm{bp}$, containing a $3^{\prime}$ UTR of 1,483 bp, a 5' UTR of $126 \mathrm{bp}$, and an ORF of 1,053 bp encoding 350 amino acids (Figure 5). The predicted molecular weight of PaPKA was $40.28 \mathrm{kDa}$ and its theoretical isoelectric point was 8.35. The nucleotide sequence was deposited in GenBank under accession number KX839259. A glycine-rich loop GTGSFGRV (amino acids 50-57), Ser/Thr active site RDLKPEN (amino acids 165-171), PKA-regulatory-subunit-binding site LCGTPEY (amino acids 198-204), DFG triplet (Asp-Phe-Gly) for orienting the $\gamma$-phosphates of adenosine triphosphate (ATP) for transfer, APE motif (Ala-Pro-Glu) to stabilize the structure of the large lobe of PKA, and conserved phosphorylation site (Thr197) were detected in this deduced amino acid sequence. The presence of these conserved regions indicated that PaPKA was the catalytic subunit of PKA. An amino acid comparison indicated that PaPKA was highly similar to other PKA catalytic subunits (Figure 6).

The predicted location of PaPKA in the cell was predominantly in the cytoplasm (47.8\%). The three-dimensional structural analysis of PaPKA showed that it folded into a two-lobed structure (Figure 7). The small lobe had a predominantly $\beta$-sheet structure, which was responsible for anchoring and orienting the nucleotide, and the large lobe had a predominantly $\alpha$-helix structure, and was primarily involved in binding the peptide substrate and initiating phosphotransfer 
224

225

226

227

228

229

230

231

232

233

234

235

236

237

238

239

240

241

242

243

244

245

246

247

248

249

250

251

252

253

254

255

256

257

258

259

260

261

262

(Hanks and Hunter, 1995). Ser53, Phe54, and Gly55 formed hydrogen bonds with ATP $\beta$ phosphate oxygens, and Leu49 and Val57 formed a hydrophobic pocket enclosing the adenine ring of ATP.

\section{Phylogenetic analysis of PaGPCR and PaPKA}

Phylogenetic trees were constructed from the amino acid sequences of GPCR and PKA, (Figure 8 and Figure 9, respectively). Figure 8 indicates that PaGPCR shared great identity with the orphan GPCRs of other polychaetes. Figure 9 shows that PaPKA shared identity with mollusk PKAs, which clustered together on a single branch.

\section{Effects of B(a)P on PaGPCR and PaPKA expression in P. aibuhitensis}

Figure 10A shows the expression of the PaGPCR gene of $P$. aibuhitensis during B(a)P exposure. There was no difference in its expression between the acetone control group and the blank control group, indicating that acetone as a solvent had no toxic effect on the nematodes. During exposure to $\mathrm{B}(\mathrm{a}) \mathrm{P}$, the expression of the $P a G P C R$ gene increased both time- and approximately dose-dependently. On day 4, PaGPCR expression was significantly upregulated $(\mathrm{P}<0.05)$ in all but the $0.5 \mu \mathrm{g} / \mathrm{L} \mathrm{B}$ (a)P group. The expression of $P a G P C R$ in the 5,10 , and $50 \mu \mathrm{g} / \mathrm{L} \mathrm{B}(\mathrm{a}) \mathrm{P}$ groups was 2.32-, 3.46-, and 3.15-fold higher than in the blank control group, respectively. On day 7, the expression of PaGPCR in the $0.5,5,10$, and $50 \mu \mathrm{g} / \mathrm{L} \mathrm{B}(\mathrm{a}) \mathrm{P}$ groups was 3.10-, 2.91-, 3.59-, and 3.28 -fold higher than in the blank control group, respectively $(P<0.05)$. The expression of $P a G P C R$ in each concentration group reached its highest level on day 14, at 4.30-, 6.60-, 4.79-, and 6.36-fold higher than the blank control group, respectively $(P<0.01)$.

The expression pattern of the $P a P K A$ gene during B(a)P exposure was the same as that of $P a G P C R$ (Figure 10B). The expression of $P a P K A$ increased as the time of exposure increased. On day 4, the expression of PaPKA was slightly higher in all but the $0.5 \mu \mathrm{g} / \mathrm{L} \mathrm{B}(\mathrm{a}) \mathrm{P}$ concentration group, at 1.79-, 1.21-, and 2.21-fold higher in the 5, 10, and $50 \mu \mathrm{g} / \mathrm{L} \mathrm{B}(\mathrm{a}) \mathrm{P}$ groups, respectively, than in the blank control group. The expression of $P a P K A$ in each concentration group was higher on day 7 than on day 4, at 1.25-, 1.90-, 2.52-, and 2.89-fold higher in the 0.5, 5, 10 , and $50 \mu \mathrm{g} / \mathrm{L} \mathrm{B}(\mathrm{a}) \mathrm{P}$ groups, respectively, than in the blank control group $(P<0.05)$. On day 14, the expression of PaPKA reached its highest level in each concentration group, at 3.19-, 5.03, 3.10-, and 5.02-fold higher than the blank control group, respectively $(P<0.05)$.

\section{Effect of B(a)P on PKA content in P. aibuhitensis}

The PKA content in $P$. aibuhitensis under B(a)P exposure was detected (Figure 11). The PKA content in each concentration group increased and reached its highest level on day 4 . The PKA content in each concentration group was $30.09,34.26,30.37$ and $26.11 \mathrm{ng} / \mathrm{mL}$, respectively, and the content of PKA in $5 \mu \mathrm{g} / \mathrm{L} \mathrm{B}(\mathrm{a}) \mathrm{P}$ concentration group was significantly higher than in the blank control group $(P<0.05)$. On day 7 , the PKA content in each concentration group was slightly higher than in the blank control group, but was downregulated than on day 4 . The PKA content in the $0.5,5,10$, and $50 \mu \mathrm{g} / \mathrm{L} \mathrm{B}(\mathrm{a}) \mathrm{P}$ groups was $24.01,24.97,21.79$ and $24.69 \mathrm{ng} / \mathrm{mL}$, respectively. On day 14 , the PKA content in the $0.5,5$ and $50 \mu \mathrm{g} / \mathrm{L} \mathrm{B}(\mathrm{a}) \mathrm{P}$ groups was still downregulated than on day 7 , but the PKA content in $10 \mu \mathrm{g} / \mathrm{L} \mathrm{B}(\mathrm{a}) \mathrm{P}$ group was slightly 
263 upregulated. The PKA content in each concentration group was 20.62, 20.90, 23.67 and 24.59

$264 \mathrm{ng} / \mathrm{mL}$, respectively.

\section{Discussion}

266 To investigate the relationship between GPCR signal transduction pathway and $\mathrm{B}(\mathrm{a}) \mathrm{P}$ exposure 267 in $P$. aibuhitensis, the full-length cDNAs of the $P a G P C \mathrm{R}$ and $P a P K A$ were isolated and 268 characterized in $P$. aibuhitensis for the first time. The sequence of $P a G P C R$ contained $1514 \mathrm{bp}$, 269 encoding 338 amino acids. The deduced protein sequence of PaGPCR contained a 7TM helix 270 bundle domain, flanked by the extracellular $\mathrm{N}$-terminal region and the intracellular C-terminus. 271 As part of the functional mechanism of GPCR, the E/DRY motif (amino acids 124-126), which 272 plays an important role in regulating the conformational state of GPCR, occurred at the border 273 between TM III and intracellular loop 2 in this sequence. The protein sequence of PaGPCR also contained the NPXXY motif (amino acids 298-302) in TM VII, which confirmed that it belonged to the rhodopsin family, the largest of the five families involved in many signaling processes (Fredriksson et al., 2003). A multiple protein sequence alignment showed that PaGPCR shared almost 33\% homology with the galanin receptor of echinoderms. A phylogenetic analysis showed that it clustered most closely with the orphan GPCRs of other polychaetes, and the galanin receptor of echinoderms. It is well-known that proteins with similar sequences often display comparable functions if the sequence identify exceeds 30\% (Kakarala and Jamil, 2014). However, the short transmembrane sequences showed relative low e values with other GPCRs. If the e-values are low, a prediction based on sequence identity and three dimension structural analysis may not be reliable. Therefore, further study for investigating ligand receptor binding is needed to prove the function of PaGPCR. In contrast to the low sequence identify of GPCR, PKA in P. aibuhitensis shared high sequence identify with the PKA catalytic subunits of other species. PaPKA contained 2,662 bp, which encoded 350 amino acids. The deduced amino acid sequence of PaPKA contained all the conserved domains that were necessary for kinase activity, such as the conserved Thr in the activation loop, the ATP-binding site (GTGSFGRV), the serine/threonine kinase active site (RDLKPEN), and the PKAregulatory-subunit-binding site (LCGTPEY). The highly conserved amino acids at the ATPbinding site played important roles in ATP binding and phosphotransfer. The high homology among the PKA catalytic subunits suggested that they have a conserved role in intracellular signaling in both vertebrates and invertebrates.

GPCRs comprise the largest and most important family of cell-surface proteins, transmitting signals from extracellular ligands. In vertebrates, they are key regulators of the innate and adaptive immune responses and have been used as potential targets in drug discovery (Garland, 2013). However, they have been inadequately investigated in invertebrates. Miller et al. (2015) reported that FSHR-1 mutants of $C$. elegans died significantly more quickly during cadmium exposure than wild-type nematodes, which suggests that the GPCR pathway protects C. elegans against pollutant damage. Dong and Zhang (2012) reported that Gram-negative bacterial infection induced the expression of the HPIR gene in Procambarus clarkia. Those results in invertebrates indicate GPCR may also play important role in immune response to environment 
303 stimulation. In the present study, we found that $\mathrm{B}(\mathrm{a}) \mathrm{P}$ exposure induced the expression of $304 P a G P C R$, which increased with time in each concentration group. This result implied that GPCR 305 may play an important role in reducing the deleterious effects of B(a)p in P. aibuhitensis. GPCRs

306

307

308

309

310

311

312

313

314

315

316

317

318

319

320

321

322

323

324

325

326

327

328

329

330

331

332

333

334

335

336

337

338

339

340

341

342

interact with diverse chemical structures, which increases cAMP production, which then stimulates phospholipase $\mathrm{C}$ activity and the subsequent mobilization of $\mathrm{Ca}^{2+}$. Mayati et al. (2012) observed an interaction between B(a)P and $\beta_{2} \mathrm{ADR}$ in endothelial HMEC-1 cells, which altered the levels of intracellular $\mathrm{Ca}^{2+}$ and the expression of cytochrome $\mathrm{P} 450 \mathrm{~B} 1$. Factor et al. (2011) observed the reduced expression and function of $\beta_{2}$ ADR in airway epithelial cells and smooth muscle cells after their exposure to a mixture of PAHs. In the present study, we observed that the expression of PaPKA in P. aibuhitensis, was higher during $\mathrm{B}(\mathrm{a}) \mathrm{P}$ exposure than the control level in all but the $0.5 \mu \mathrm{g} / \mathrm{L} \mathrm{B}(\mathrm{a}) \mathrm{p}$ concentration group. The expression of PaPKA was significantly and exposure-time-dependently induced by $50 \mu \mathrm{g} / \mathrm{L} \mathrm{B}(\mathrm{a}) \mathrm{P}$. Besides the gene expression of $P a P K A$, the PKA content was also detected in this study, the PKA content in $P$. aibuhitensis under $\mathrm{B}(\mathrm{a}) \mathrm{P}$ exposure was upregulated on day 4. Kreiling et al. (2004) reported exposure to a mixture of bromoform, chloroform and tetrachloroethylene increased cAMPdependent protein kinase in Spislula solidissima embryos. PKA was implicated in regulation of invertebrate haemocyte activity as well as humoral immune response. The increase of PKA combined with GPCR indicated that GPCR pathway in P. aibuhitensis was affected by PAHs. After day 4 the PKA content in B(a)P concentration group still higher than in the blank control group, but was downregulated compared to day 4. However, the gene expression of PaPKA was time-dependent, the inconsistency of gene expression and protein content showed that there is no simple linear relationship between transcription and translation levels. We speculated that during short time exposure (4 day), the metabolic detoxification in P.aibuhitensis was significantly upregulated in order to reduce the toxic effect of PAHs. With time prolonging the organism tends to homeostasis, so the PKA content was not increased continuously.

$\mathrm{B}(\mathrm{a}) \mathrm{P}$ can be metabolized by organisms through a series of enzymatic and nonenzymatic reactions. Typically, B(a)P is metabolized by the phase I enzyme cytochrome P450 (CYP) and phase II enzymes such as glutathione S-transferase (GST). The induction of CYP gene expression has been detected in P. aibuhitensis (Chen et al., 2012; Zhao et al., 2014). In vertebrates, the induction of the CYP enzymes involved in the biotransformation of PAHs is mediated by the aryl hydrocarbon receptor (AhR) pathway. Both $\alpha$ - and $\beta$-type AhR proteins have been reported in bivalves (Fabbri and Capuzzo, 2010). However, no AhR homologues have been identified in other invertebrates, including marine polychaetes (Jorgensen et al., 2008). Ferrec and Ovrevik (2018) reported that a number of GPCR ligands contain aromatic structures, and that B(a)p modulates the concentration of intracytosolic cAMP through the GPCR pathway without the involvement of conventional nuclear receptors. In this study, we demonstrated the induction of GPCR and PKA expression during B(a)p exposure, so we hypothesized that the GPCR pathway is also involved in the biotransformation of PAHs in $P$. aibuhitensis. Further study of the relationship between GPCR and CYP expression is required to test our hypothesis.

Peer) reviewing PDF | (2019:07:38998:1:1:NEW 8 Oct 2019) 
343 Conclusions

344 GPCR represents a critical point of contact between cells and their surrounding environments.

345 This is the first study in which P. aibuhitensis GPCR and PKA cDNAs have been cloned. We

346 have also demonstrated that the expression of GPCR and PKA was induced in P. aibuhitensis by

347 B(a)p exposure, and that their expression was affected, to some extent, by the B(a)p

348 concentration and the exposure time. These results should be useful in investigating the

349 biotransformation of PAHs by marine polychaetes.

350

351

352

353

354

355

356

357

358

359

360

361

362

363

364

365

366

367

368

369

370

371

372

373

374

375

\section{Acknowledgements}

This work was funded by the National Natural Science Foundation of China (No. 41306138), the key laboratory of mariculture and stock enhancement in North China's Sea, Ministry of Agriculture and Rural Affairs, Dalian Ocean unverisity, P. R. China(2018-KF-15) and Liaoning Scientific instrument sharing Platform(L201810).

\section{References}

Bainy AC. 2007. Nuclear receptors and susceptibility to chemical exposure in aquatic organisms.Environment International 33(4):571-575 DOI 10.1016/j.envint.2006.11.004

Chen X, Zhou YB, Yang DZ, Zhao H, Wang LL,Yuan XT. 2012. CYP4 mRNA expression in marine polychaete Perinereis aibuhitensis in response to petroleum hydrocarbon and deltamethrin. Marine Pollution Bulletin 64(9):1782-1788 DOI 10.1016/j.marpolbul.2012.05.035

Dong C, Zhang P. 2012. A putative G protein-coupled receptor involved in innate immune defense of Procambarus clarkii against bacterial infection. Comparative Biochemistry and Physiology A Molecluar and Integrative Physiology 161(2):95-101 DOI 10.1016/j.cbpa.2011.09.006

Fredriksson R, Malin CL, Lundin LG, Helgi BS. 2003. The G-protein-coupled receptors in the human genome form five main families. Molecular Pharmacology 63(6):1256-1272 DOI 10.1124/mol.63.6.1256

Factor P, Akhmedov AT, McDonald JD, Qu A, Wu J, Jiang H, Dasgupta T, Panettieri Jr RA, Perera F, Miller RL. 2011. Polycyclic aromatic hydrocarbons impair function of b2adrenergic receptors in airway epithelial and smooth muscle cells. American Journal of Respiratory Cell and Molecular Biology 45(5):1045-1049 DOI 10.1165/rcmb.2010-0499OC

Fabbri E, Capuzzo A. 2010. Cyclic AMP signaling in bivalve molluscs: an overview. Journal of Experimental Zoology Part A Ecological Genetics and Physiology 313A(4):179-200 DOI $10.1002 /$ jez.592 
376 Ferrec E, Øvrevik J. 2018. G-protein coupled receptors (GPCR) and environmental exposure. 377 Consequences for cell metabolism using the $\beta$-adrenoceptors as example. Current Opinion in 378 Toxicology 8:14-19 DOI 10.1016/j.cotox.2017.11.012

379 Garland SL. 2013. Are GPCRs still a source of new targets? Journal of Biomolecular Screening 380

381

382

383

384

385

386

387

388

389

390

391

392

393

394

395

396

397

398

399

400

401

402

403

404

405

406

407

408

409

\section{8:947-966 DOI 10.1177/1087057113498418}

Hanks SK, Hunter T. 1995. Protein kinases 6. The eukaryotic protein kinase superfamily: kinase (catalytic) domain structure and classification. The Faseb Journal 9(8):576-596 DOI 10.1096/fasebj.9.8.7768349

Jorgensen A, Giessing AMB, Rasmussen LJ, Andersen O. 2008. Biotransformation of polycyclic aromatic hydrocarbons in marine polychaetes. Marine environmental 65 (2): 171186 DOI 10.1016/j.marenvres.2007.10.001

Kakarala KK, Jamil K. 2014. Sequence-structure based phylogeny of GPCR Class A Rhodopsin receptors. Molecular Phylogenetics and Evolution 2,74:66-96 DOI 10.1016/j.ympev.2014.01.022

Kreiling JA , Stephens RE , Reinisch CL. 2005.A mixture of environmental contaminants increases cAMP-dependent protein kinase in Spisula embryos. Environmental Toxicology and Pharmacology, 19(1):9-18. DOI 10.1016/j.etap.2004.02.007

Li WJ, Xue SL, Pang Min, Yue ZH, Yang DZ, Zhou YB, Zhao H. 2018. The expression characteristics of vitellogenin(VTG) in response to B(a)p exposure in polychaete Perinereis aibuhitensis. Journal of Oceanology and Limnology 36(06):399-409 DOI 10.1007/s00343019-7304-0

\section{Miller RL, Thompson AA, Trapella C, Guerrini R, Malfacini D, Patel N, Han GW} Cherezov V, Caló G, Katritch V, Stevens RC. 2015. The importance of ligand-receptor conformational pairs in stabilization: spotlight on the N/OFQ G protein-coupled receptor. Structure 23(12): 2291-2299 DOI 10.1016/j.str.2015.07.024

\section{Mayati A, Levoin N, Paris H, N'Diaye M, Courtois A, Uriac P, Lagadic-Gossmann} D,Fardel O, Le Ferrec E. 2012. Induction of intracellular calcium concentration by environmental benzo(a)pyrene involves a b2-adrenergic receptor/adenylyl cyclase/Epac1/inositol 1,4,5-trisphosphate pathway in endothelial cells. Journal of Biological Chemistry 287(6):4041-4052 DOI 10.1074/jbc.M111.319970

Nadal A, Ropero AB, Laribi O, Maillet M, Fuentes E, Soria B. 2000. Nongenomic actions of estrogens and xenoestrogens by binding at a plasma membrane receptor unrelated to estrogen receptor alpha and estrogen receptor beta. Proceedings of the National Academy of Sciences 97(21):11603-11608 DOI 10.1073/pnas.97.21.11603

Peer) reviewing PDF | (2019:07:38998:1:1:NEW 8 Oct 2019) 
410 Yang D, de Graaf C, Yang L, Song G, Dai A, Cai X, Feng Y, Reedtz-Runge S, Hanson

411 MA, Yang H, Jiang H, Stevens RC, Wang MW. 2016. Structural determinants of binding

412 the seven-transmembrane domain of the glucagon-like peptide-1 receptor. Journal of

413 Biological Chemistry 291(25):12991-13004 DOI 10.1074/jbc.M116.721977

414 Zhang JH. 2008. Quality benchmark study of polycyclic aromatic hydrocarbons in marine 415 sediments. Doctoral dissertation. Dalian Maritime University.

416 Zhao H, Zhao XD, Yue ZH, Zhou YB. 2014. Effects of Benzo(a)pyrene on Antioxidant

417 Enzyme Activity and Cytochrome P450 Gene Expression in the Perinereis aibuhitensis.

418 Journal of Dalian Ocean University 29(4):342-346 DOI 10.3969/J.ISSN.2095-

$419 \quad 1388.2014 .04 .004$

420 
Figure 1

Nucleotide sequence and deduced amino acid sequence of GPCR from Perinereis aibuhitensis.

Initiation codon (ATG) and termination codon (TAA) are highlighted in red boxes; The seventransmembrane (7TM ) domains (TM I to TM VII) are underlined with red lines. The E/DRY and NPXXY motifs are in shadow. 


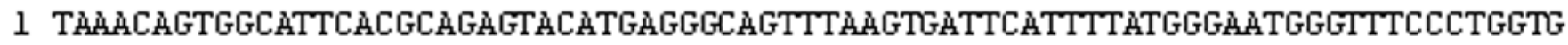

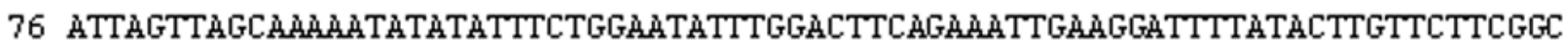

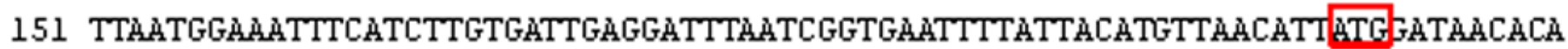

1 $\begin{array}{lllll}M & D & N & T\end{array}$

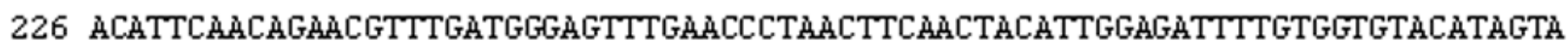
$\begin{array}{llllllllllllllllllllllllllll}5 & \mathrm{~T} & \mathrm{~F} & \mathrm{~N} & \mathrm{R} & \mathrm{T} & \mathrm{F} & \mathrm{D} & \mathrm{G} & \mathrm{S} & \mathrm{L} & \mathrm{N} & \mathrm{P} & \mathrm{N} & \mathrm{F} & \mathrm{N} & \mathrm{Y} & \mathrm{I} & \mathrm{G} & \mathrm{D} & \mathrm{F} & \mathrm{V} & \mathrm{V} & \mathrm{Y} & \mathrm{I} & \mathrm{V}\end{array}$

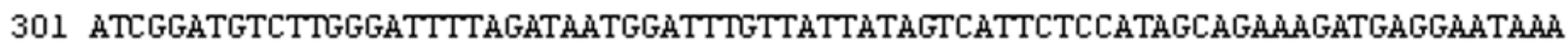

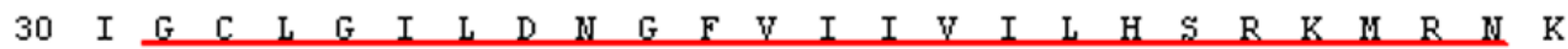

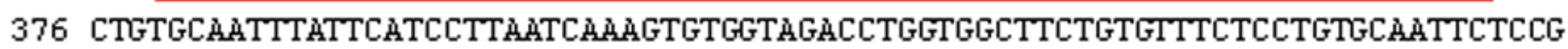

$\begin{array}{llllllllllllllllllllllllll}55 & \mathrm{~L} & \mathrm{C} & \mathrm{N} & \mathrm{L} & \mathrm{F} & \mathrm{I} & \mathrm{L} & \mathrm{N} & \mathrm{Q} & \mathrm{S} & \mathrm{V} & \mathrm{V} & \mathrm{D} & \mathrm{L} & \mathrm{V} & \mathrm{A} & \mathrm{S} & \mathrm{V} & \mathrm{F} & \mathrm{L} & \mathrm{L} & \mathrm{C} & \mathrm{N} & \mathrm{S} & \mathrm{P}\end{array}$ 451 TCTGTTCCGACCTTAGGGTCAGCGTCGÄTATTÄGTCTGGÄGTTTATTGCCGCATTTGGGATTCGAACTATCTC

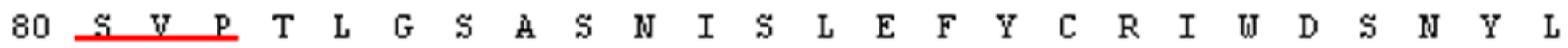
526 TTCTGGGCTGCCGTCACATGGTCAACTTACAACTTAGTCGCCATCACÄACGAACGTTACTTAGÄGGTCGTTCAC $\begin{array}{lllllllllllllllllllllllllll}105 & \mathrm{~F} & \mathrm{~W} & \mathrm{~A} & \mathrm{~A} & \mathrm{~V} & \mathrm{~T} & \mathrm{~W} & \mathrm{~S} & \mathrm{~T} & \mathrm{Y} & \mathrm{N} & \mathrm{L} & \mathrm{V} & \mathrm{A} & \mathrm{I} & \mathrm{T} & \mathrm{I} & \mathrm{x} & \mathrm{K} & \mathrm{Y} & \mathrm{L} & \mathrm{E} & \mathrm{V} & \mathrm{V} & \mathrm{H}\end{array}$ 601 CСACTTCGGTACAGATCATTCTTCACGCGGAGACGTGCAдAGGTCATTGTCGCTGTCGTCTGGTTGGTTGGATTC \begin{tabular}{llllllllllllllllllllllllll}
130 & $\mathrm{P}$ & $\mathrm{L}$ & $\mathrm{R}$ & $\mathrm{Y}$ & $\mathrm{R}$ & $\mathrm{S}$ & $\mathrm{F}$ & $\mathrm{F}$ & $\mathrm{T}$ & $\mathrm{R}$ & $\mathrm{R}$ & $\mathrm{R}$ & Aे & $\mathrm{K}$ & $\mathrm{V}$ & $\mathrm{I}$ & $\mathrm{V}$ & A & $\mathrm{V}$ & $\mathrm{V}$ & $\mathrm{U}$ & $\mathrm{L}$ & $\mathrm{V}$ & $\mathrm{G}$ & $\mathrm{F}$ \\
\hline
\end{tabular} 676 ACCATACCTATCGTGACGTCAGTTATCACCAGTCCTGCGGGAGCAGACGGCACTTGTCAGAมGCACAGAGCGTGG $\begin{array}{lllllllllllllllllllllllllll}155 & \mathrm{~T} & \mathrm{I} & \mathrm{P} & \mathrm{I} & \mathrm{V} & \mathrm{T} & \mathrm{S} & \mathrm{V} & \mathrm{I} & \mathrm{T} & \mathrm{S} & \mathrm{P} & \mathrm{A} & \mathrm{G} & \text { A } & \mathrm{D} & \mathrm{G} & \mathrm{T} & \mathrm{C} & \mathrm{Q} & \mathrm{K} & \mathrm{H} & \mathrm{R} & \text { A } & \mathrm{W}\end{array}$ 751 TCCTCCCGACTCATGGCTGCCCTCGTAGGATTTTACGCCCTCTTCTTCGGATTTCTTTTACCTGTCGTCATAATG \begin{tabular}{lllllllllllllllllllllllllll}
180 & $S$ & $S$ & $R$ & $L$ & $M$ & Aे & A & $L$ & $V$ & $G$ & $F$ & $Y$ & Aे & L & $F$ & $F$ & $G$ & $F$ & L & L & P & $V$ & $V$ & $I$ & $M$ \\
\hline
\end{tabular}

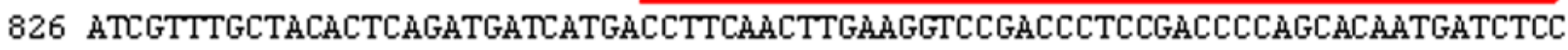
$\begin{array}{llllllllllllllllllllllllll}205 & \mathrm{I} & \mathrm{V} & \mathrm{C} & \mathrm{Y} & \mathrm{T} & \mathrm{Q} & \mathrm{M} & \mathrm{I} & \mathrm{M} & \mathrm{T} & \mathrm{F} & \mathrm{N} & \mathrm{L} & \mathrm{K} & \mathrm{V} & \mathrm{R} & \mathrm{P} & \mathrm{S} & \mathrm{D} & \mathrm{P} & \mathrm{S} & \mathrm{T} & \mathrm{M} & \mathrm{I} & \mathrm{S}\end{array}$

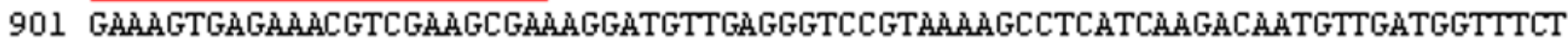
$\begin{array}{lllllllllllllllllllllllllll}230 & E & S & E & K & R & R & S & E & R & M & L & R & V & R & K & S & L & I & K & T & M & L & M & V & S\end{array}$

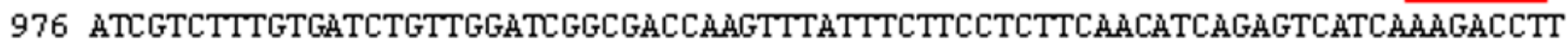

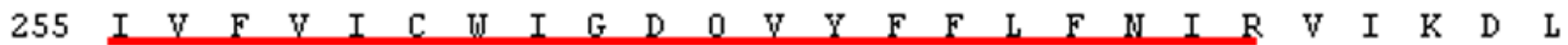

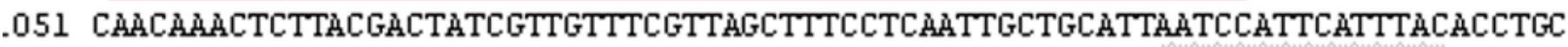
$\begin{array}{lllllllllllllllllllllllllll}280 & \mathrm{Q} & \mathrm{Q} & \mathrm{T} & \mathrm{L} & \mathrm{T} & \mathrm{T} & \mathrm{I} & \mathrm{V} & \mathrm{V} & \mathrm{S} & \mathrm{L} & \mathrm{A} & \mathrm{F} & \mathrm{L} & \mathrm{N} & \mathrm{C} & \mathrm{C} & \mathrm{I} & \mathrm{H} & \mathrm{F} & \bar{x} & \mathrm{r} & \ddot{x} & \mathrm{~T} & \mathrm{C}\end{array}$

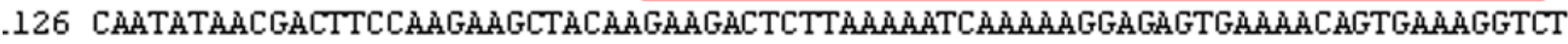
$\begin{array}{lllllllllllllllllllllllllll}305 & \mathrm{Q} & \mathrm{Y} & \mathrm{N} & \mathrm{D} & \mathrm{F} & \mathrm{Q} & \mathrm{E} & \mathrm{A} & \mathrm{T} & \mathrm{R} & \mathrm{R} & \mathrm{L} & \mathrm{L} & \mathrm{K} & \mathrm{I} & \mathrm{K} & \mathrm{K} & \mathrm{E} & \mathrm{S} & \mathrm{E} & \mathrm{N} & \mathrm{S} & \mathrm{E} & \mathrm{R} & \mathrm{S}\end{array}$

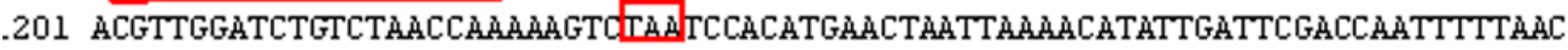

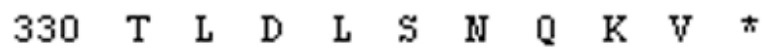

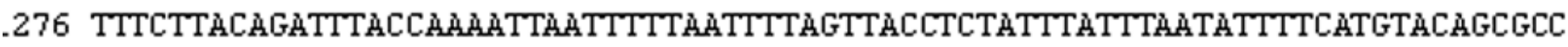

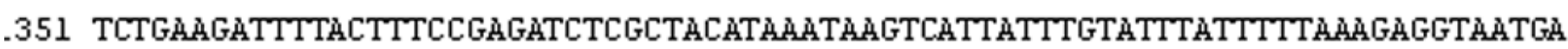

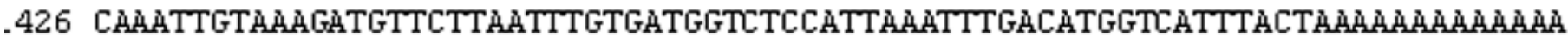

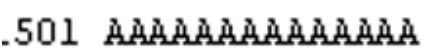




\section{Figure 2}

Multiple alignment analysis of PaGPCR with other GPCR protein.

Amino acid residues that are conserved in at least of $50 \%$ sequence are shaded and similar amino acids are shaded in dark. The GenBank accession number for these proteins are as follows: (Platynereis dumerilii orphan G protein coupled receptor, 56AKQ63061.1; Strongylocentrotus purpuratus galanin receptor type 2-like, XP_003727596.1;Acanthaster planci galanin receptor type 2-like,XP022098630.1; Apostichopus japonicus putative galanin receptor type 2-like,PIK48567.1).

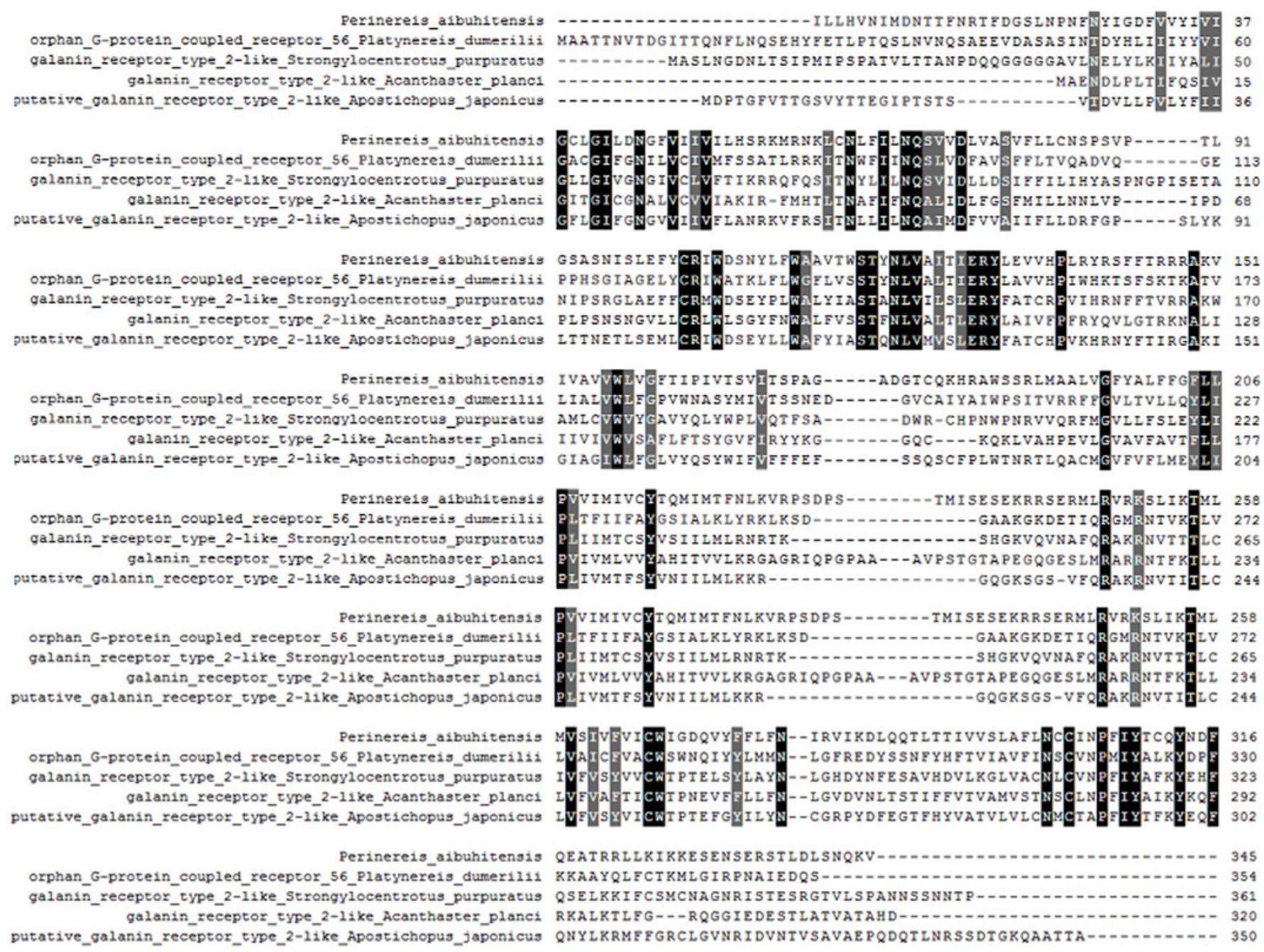

Peer) reviewing PDF | (2019:07:38998:1:1:NEW 8 Oct 2019) 
Figure 3

Analysis of transmembrane region of PaGPCR.

The whole sequence is labeled as inside (blue line) or out side (pink line), and the transmembrane region was labeled with red line.

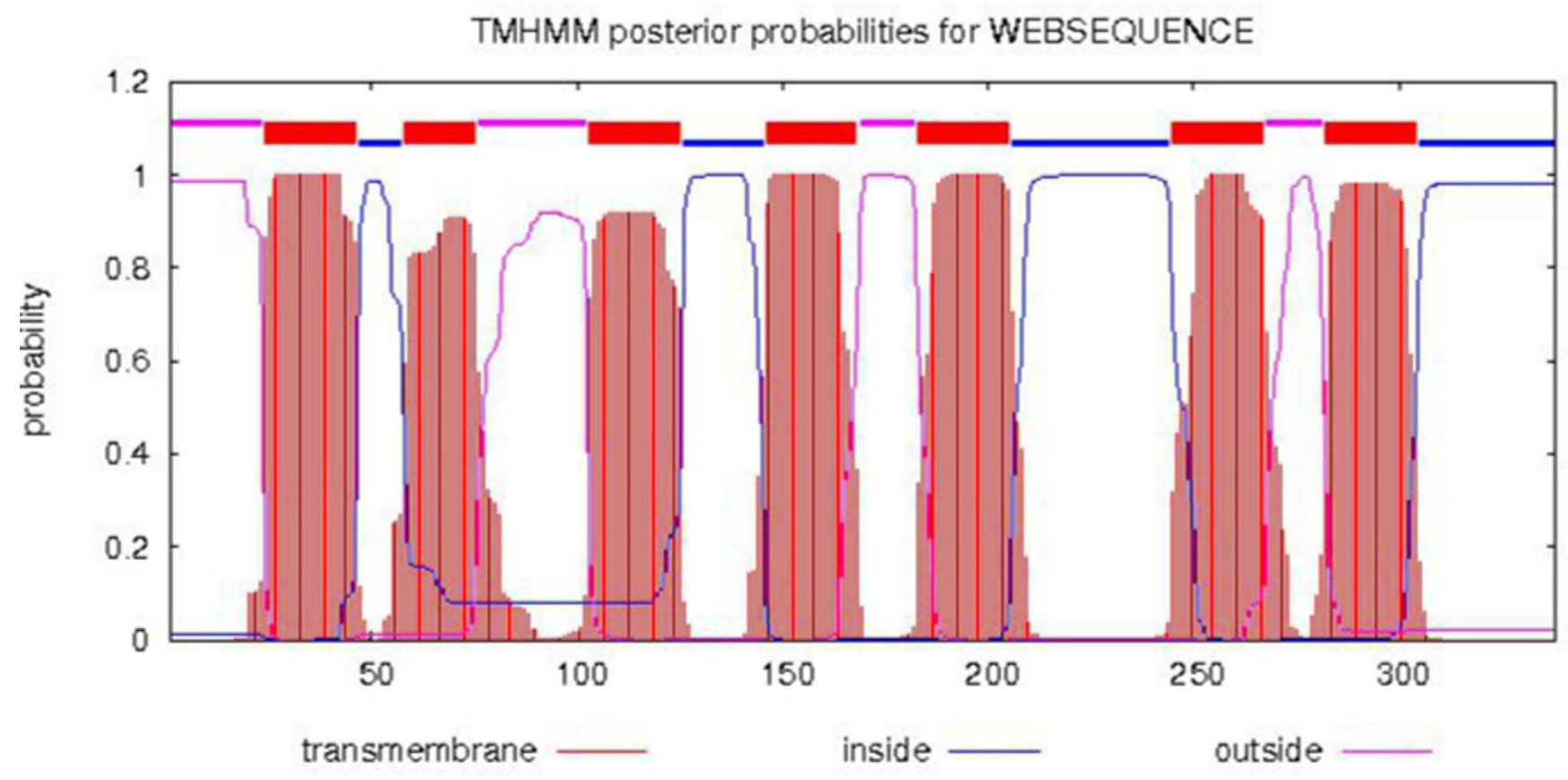


Figure 4

The three dimensional structure of PaGPCR.

The helix is colored by blue, the sheet is colored by magenta, and the loop is colored by salmon.

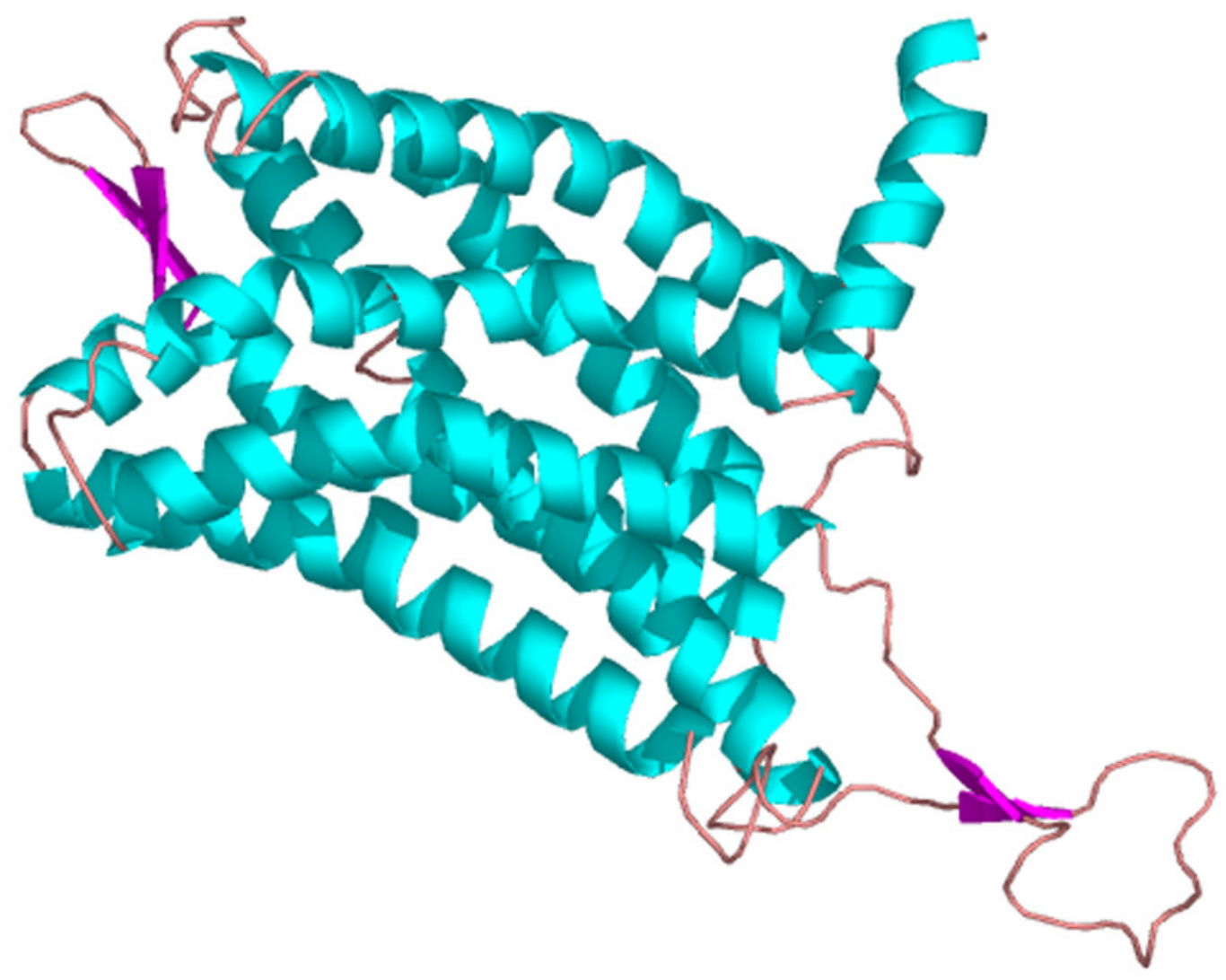




\title{
Figure 5
}

\section{Nucleotide sequence and deduced amino acid sequence of PaPKA}

\author{
Initiation codon (ATG) and termination codon (TGA) are highlighted in red boxes;
}

conservative phosphorylation site, DFG triplet and APE motif are highlighted in green boxes;

the glycine-rich loop GTGSFGRV (50-57aa), Ser/Thr active site RDLKPEN (165-171aa), PKA-

regulatory-subunit-binding site LCGTPEY (198-204aa) are underlined with red.

1 GTCGAAGAGATCGAGGTGGAATATTCAGACATAATTTTTGAGAAGCTGGTTCTGAGAGTTCTCTGATTTCTGGCCGGTTAATTCCTCTGGATCACCACGGACTAG

106 GTAGTTACCACACGGTAGCOATGGAAATGCTGCAACAGCAAAGAAAGGCGATCCAGAGAATGTCAAAGAGTTCTTAGCCAAAGCTAAAGAGGACTTCAACAAG

1

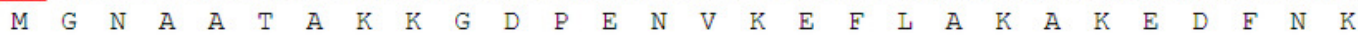

211 AAATGGGA_AGAGCATCATGTAACACTGCATCACTAGATGACTTCGACAGAATTAAAACCCTGGGAACAGGGTCATTTGGACGGGTCATGCTGGTTCAGCACAAA

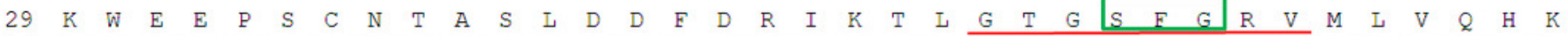

316 GCCACGAAGGAGTACTATGCCATGAAGATTTTAGATAAACAAAAGGTAGTGAAACTGAAGCAAGTTGAACACACATTGAATGAAAAGAAAATTCTGTCCGCCATA

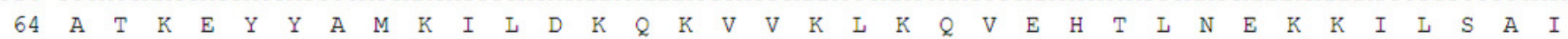

421 TCATTTCCATTCTTAGTGAGCCTAGAGTACAGTTTTAAGGATAACTCAAATTTGTACATGGTATTGGAGTTCGTGACAGGAGGTGAAATGTTCTCACATCTGCGA

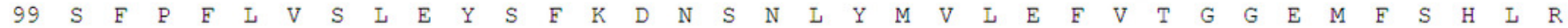

526 AGAATTGGCCGATTTAGTGAAACTCACAGCCGATTTTATGCTGCACAAGTATGCATGGTATTTGAATATCTGCACAATCTAGACACACTGTACAGAGATTTGAAG

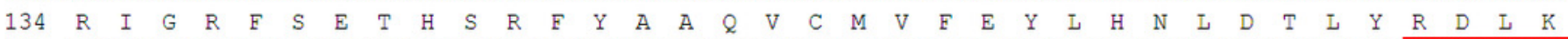

631 CCAGAAAATATTCTGATTGATGACACTGGTCACTTGAGAGTAACAGACTTCGGTTTTGCCAAACGCGTAAAAGGCAGGACATGGACGTTGTGTGGCACACCAGAG

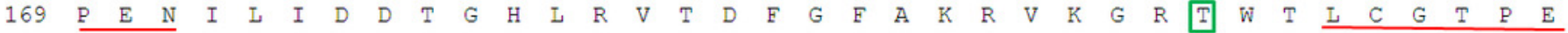

736 TACCTGGCCCCAGAAATCATCTTGAGCAAGGGCTACAACAAAGCCGTAGACTGGTGGGCGCTTGGAGTCCTTGTTTATGAAATGGCAGCTGGATACCCACCTTTC

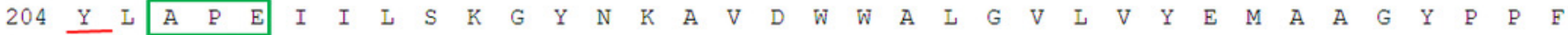

841 TTTGCTGACCAGCCAATCCAAATCTATGAGAAGATTGTCTCAGGAAAGGTGCGCTTCCCATCTCACTTTAGTTCTGATTTGAAGGATCTTTTGAAGAATCTGCTA

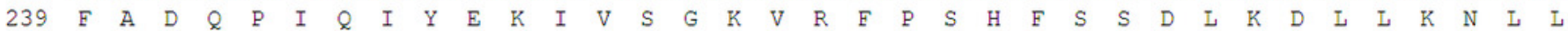

946 CAGGTAGACTTGACAAAACGTTATGGAAACCTGAAGAATGGGGTCAACGATATCAAGAATCACAAGTGGTTCTCCACCACAGACTGGATTGCTATCTACCAGAAA

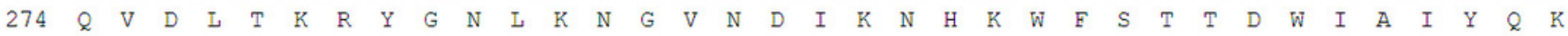

1051 AAGGTTGAAGCACCCTTCATTCCCAAGTGCAAAGGCCCAGGTGACTACAGCAACTTTGATGACTATGAGGAAGAACCACTGAGAATTTCGTCAACGGAAAAATGT

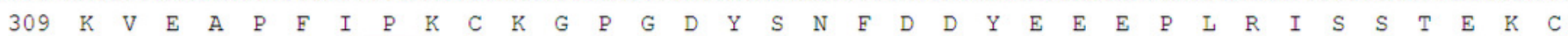

1156 GCCAAGGAGTTTGCAGACTTCIGA_GACAGTTGGCTTGTAGGTGGCTAGTGTGTGTTGGGGGAACTAAAGACTGTGATGACCATTCTGTGTTCATGGTCTATCACT

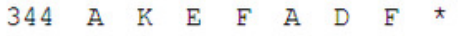

1261 GGCAGCTGGCTGAAGATCTGCGGCCCACATACCACACAATCTCTCAAAGAATACATCCTTTGTGCATTAACAAATGTATATATACTTAATCATATCACATTGCGT 1366 AATTGTAACAAGGTGAATTCAGTTTCATATGTGTCAATGAGGTAAGAGAGAGGGCTTCGATCCCAGGTGTGGCATGTCCCTGAGGCTGCGCTATTGGTCCGAGGT 1471 AAGCCAGGTCGCTTCAGCTCGCACCCCAGGCTGCCTCAAAAGCTACCTTGGTCGTCTACTCGCCGAACTAGTCATTTACCTTGCTGTGTGGCCTTCCAGATTTGT 1576 GTGGGGCAGACTGGTGGAGGATTAGGCTTTAATTGCTTTGCTGAAGTGCCCCACACGGGTCCAGAAGCCAAGGCTATCTTCAAATACACAGTTAATACCATATAT 1681 TAACTTATCATTACAACCTTACTGACCACTTGTTCACATTTAGGTCATTGTCTGCACTTTTATTGTATACAGGTGGTCCATCTGAAACAATTCTCTGAACATTTG 1786 AATTATATCCATTGTAAGGAAGTGCAAACTTCTCTTGTGCTGTGCTCCTCTCCACTCCCGTGCTGCTTCTTTCTCTGCTGTGAACTTTGAATCAGAGAGAAACAA 1891 CACTTTATTTGTATGATGTCAAATATTGTACTTTTGGTAAGGCCACCTCCTAACTGGGTGGTCATCAAGACTTGTATATAGTTTGTGAGCAGTTGGCTTTTGGGT 1996 AGAGTAGGAGTTTTCTGTTCATCATACTGGTGGGATGACACCATCTCCCGCATACCAGTAGTACTGTGTAGTAGCAATAGCCGGCCATAAGGCCTATGAGTCTCC 2101 ATTGTTTCAGCTAATGTAGCTAGGCTTCAAGTCATAAGTCATGATAACATATAATGGCATTATTTGTAGTACTGATGATGAGAGAATATTATCTTTGTCAAGACA 2206 AACTTATTTTACTTTTATATAACTGACTTGTATGTACAGACGTCAAGGCTGTATGAACTGAGAAATTGTTGCTTGTTATGTGTAGTGTATAAAATGTGTATATCT 2311 ATCTCTGCATATTTTGTGTTTGATTGTCAATCCACAAATGCTTCAAATTTATCTTGAAACCATGTACTTGACTAATCTAATTTGTGATTTGAAAAGGTAATTGGA 2416 GTTGTGCTGAATTAGATAGGTATGCTTCCTGACATTGTGTAACACTACTACAGTGAGTCCCATTTGTCATGGGTCCTACTCATGAATGTTGTTATATTTTGTATA 2521 TACTAAAAATAATTTATGCTGGTTCATGAAGATGTACAAAAAAATATTTTTCAAATGGCTAAGGATGGTTTTGATGAAATTGTTACACTAAGGGTCAGCAGTTAA 2626 CAAACCCCATGAAAAAAAAAAAAAAAAAAAAAAAAAA 


\section{Figure 6}

Multiple alignment of PaPKA with other PKA.

Amino acid residues that are conserved in at least of 50\% sequence are shaded and similar amino acids are shaded in dark. The GenBank accession number for these proteins are as follows: Aplysia califormica catalytic subunit of PKA, NP_001191420.1; Xenopus tropicalis CAMP depedent protein kinase catalytic subunit, NP_001164667.1; Branchiostoma floridae CAMP depedent protein kinase, XP_002600447.1; Danio rerio CAMP depedent protein kinase catalytic subunit, NP_001030148.1; Octopus bimaculoides CAMP depedent protein kinase catalytic subunit, XP_014777153.1; Lingula anatina CAMP depedent protein kinase catalytic subunit, XP_013409439.1; Crassostrea gigas cAMP depedent protein kinase catalytic subunit, XP_011439335.1; Biomphalaria glabrata CAMP depedent protein kinase catalytic subunit, XP_013072294.1; Salmo salar cAMP depedent protein kinase catalytic subunit, XP_014071121.1; Gallus gallus CAMP depedent protein kinase catalytic subunit, XP_015146370.1. 

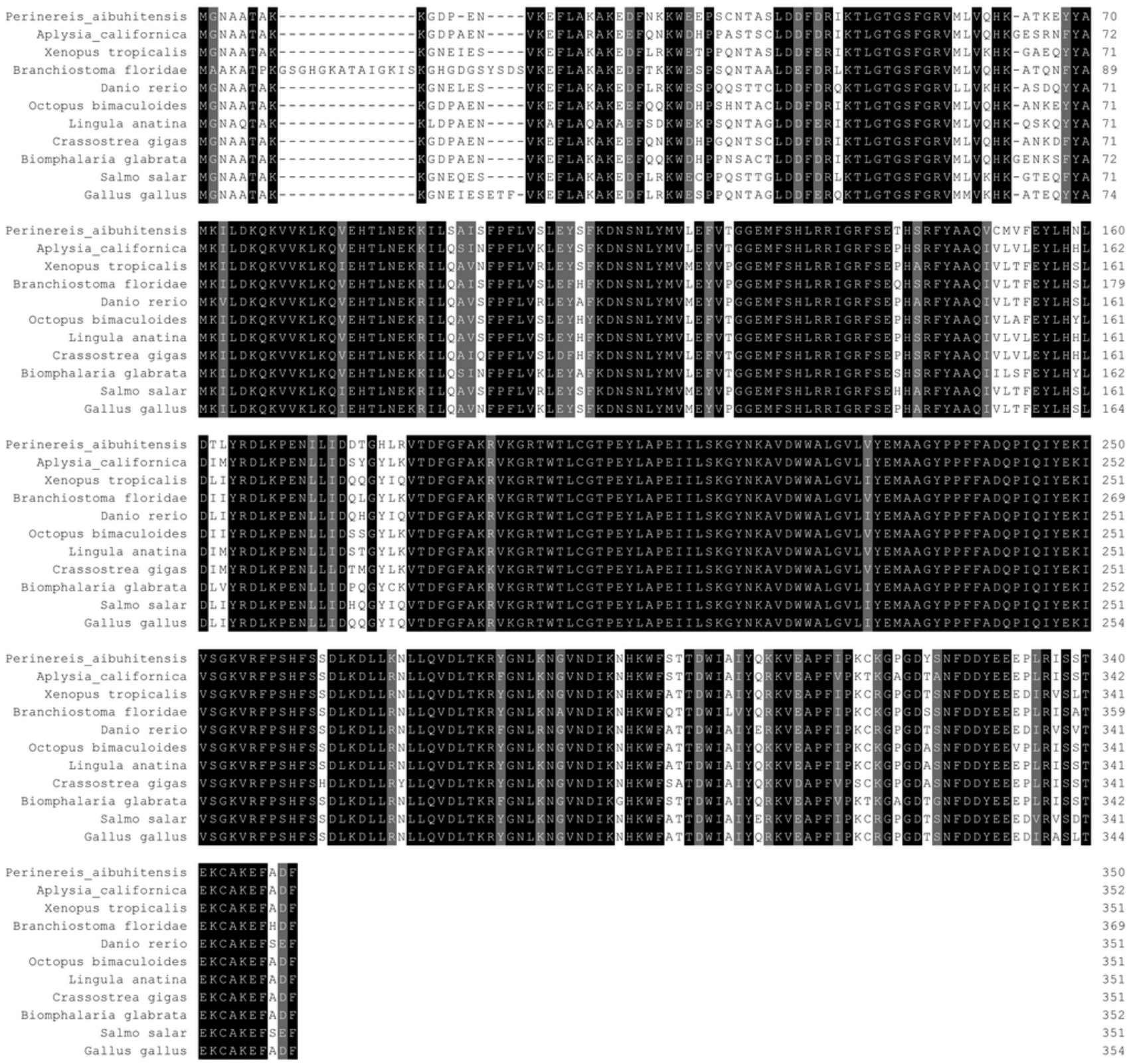
Figure 7

The three dimensional structure of PKA from $P$. aibuhitensis.

The helix is colored by blue, the sheet is colored by magenta, and the loop is colored by salmon, DFG triplet is labeled in magenta.

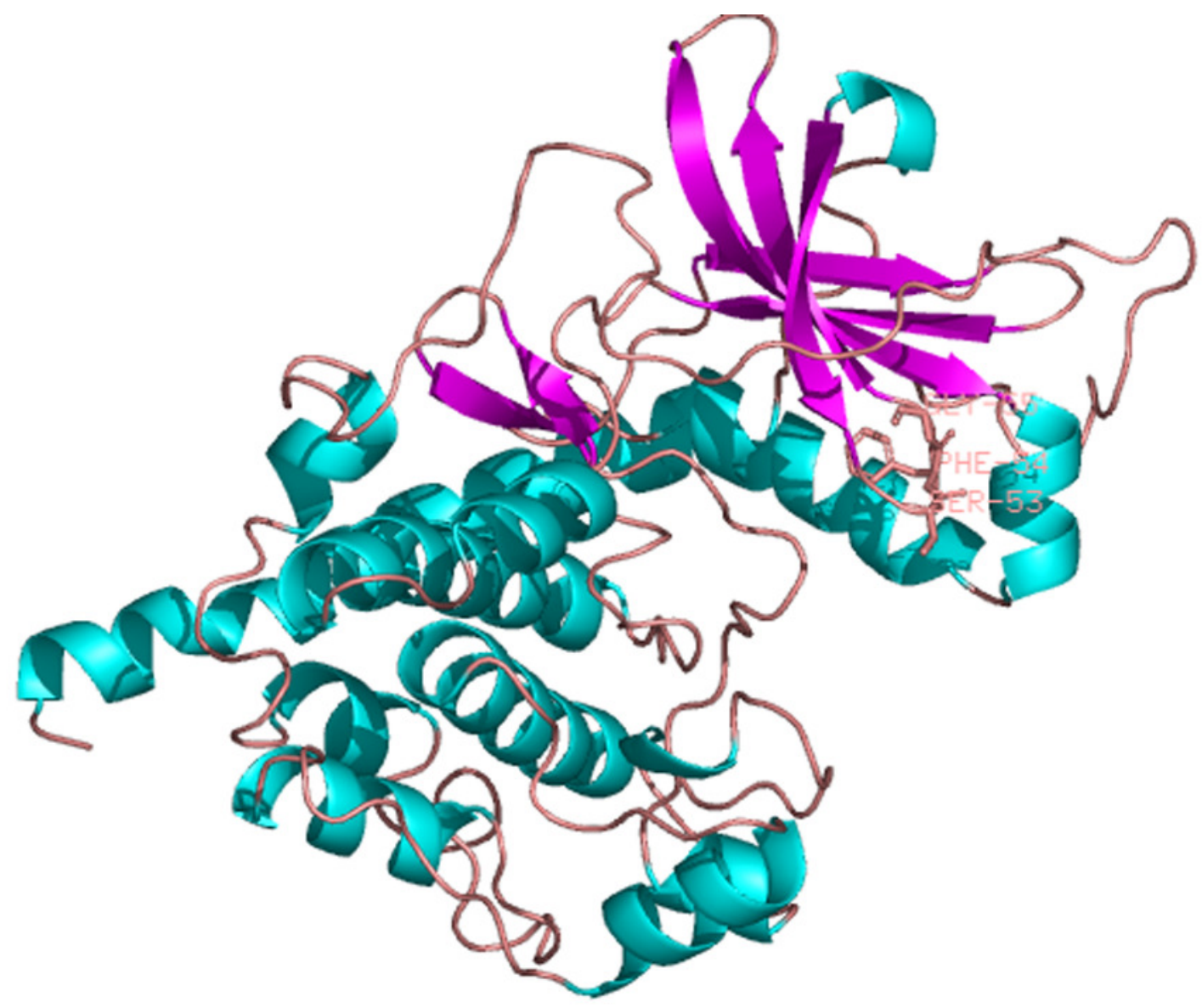


Figure 8

Phylogenetic analysis of PaGPCR related to GPCR of other invertebrates and vertebrates.

The information of other GPCR are same as the information in Figure 2; the tree topologies were evaluated with 1,000 replicates.

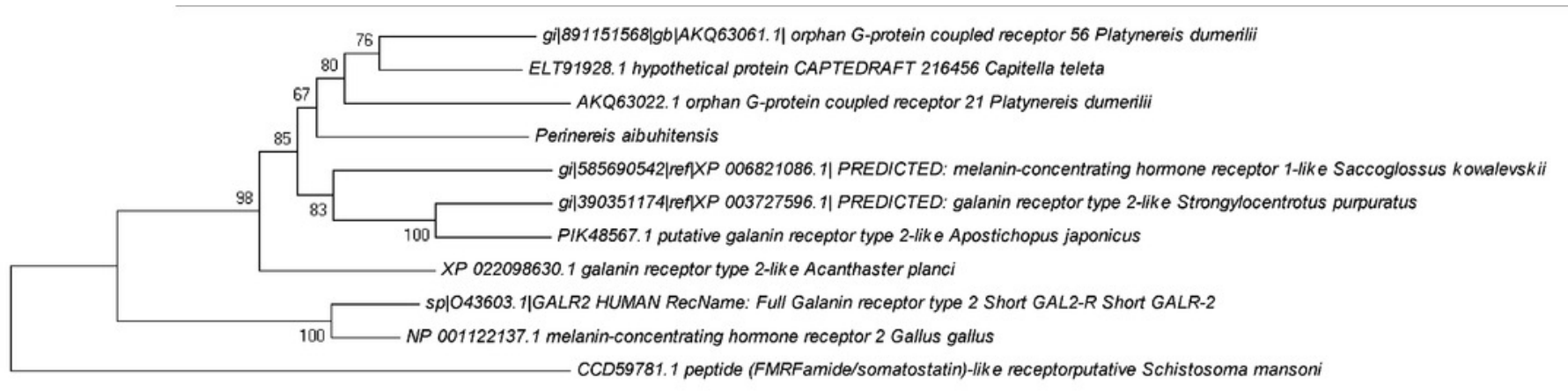

$\longmapsto 0.2$ 
Figure 9

Phylogenetic analysis of PaPKA related to PKA of other invertebrates and vertebrates.

The information of other PKA sequence are as the information in Figure 6; the tree topologies

were evaluated with 1,000 replicates.

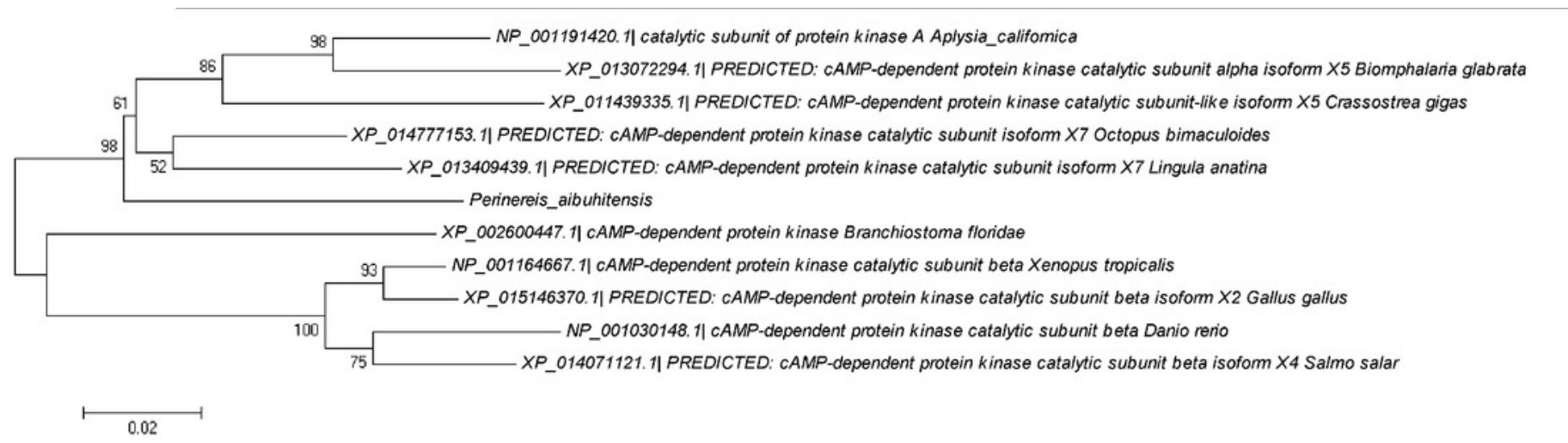


Figure 10

The relative expression level of $P a G P C R$ and PaPKA cDNAs under various $\mathrm{B}(\mathrm{a}) \mathrm{P}$ concentration exposure.

A represents PaGPCR, B representsPaPKA.Different lowercase letters indicate significant difference $(P<0.05)$. all data as mean+SD. $N=$ four worms.

A

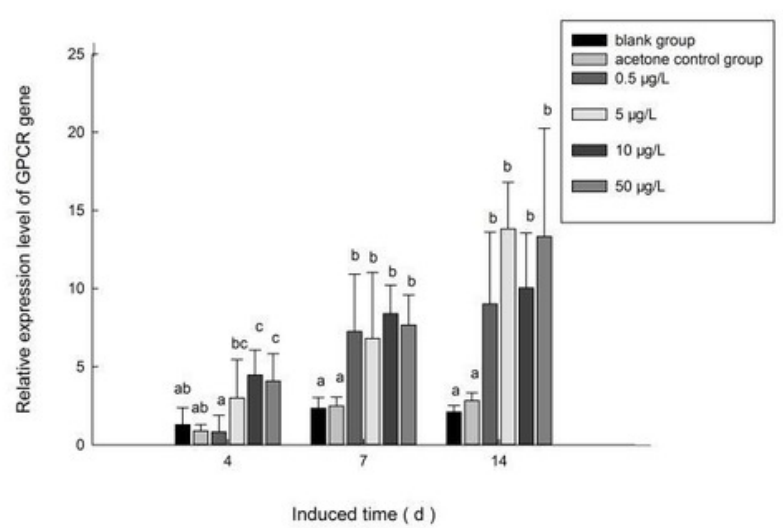

B

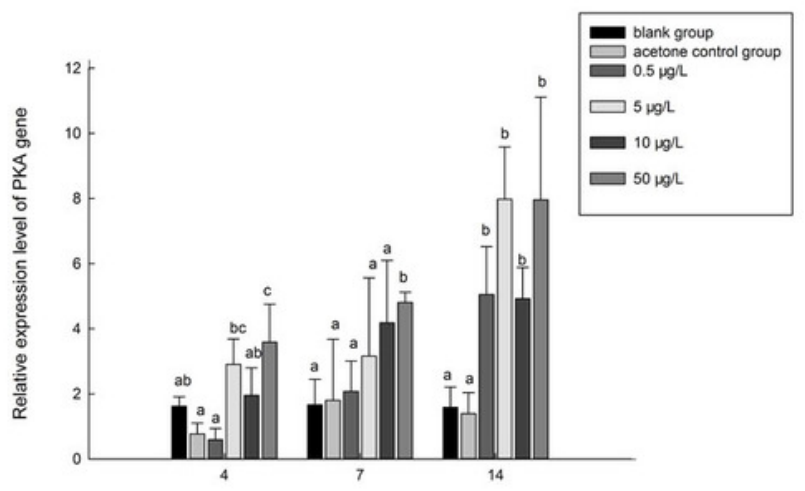

Induced time (d) 


\section{Figure 11}

The PKA content under various B(a)P concentration exposure.

Different lowercase letters indicate significant difference $(P<0.05)$. all data as mean+SD.N= three worms.

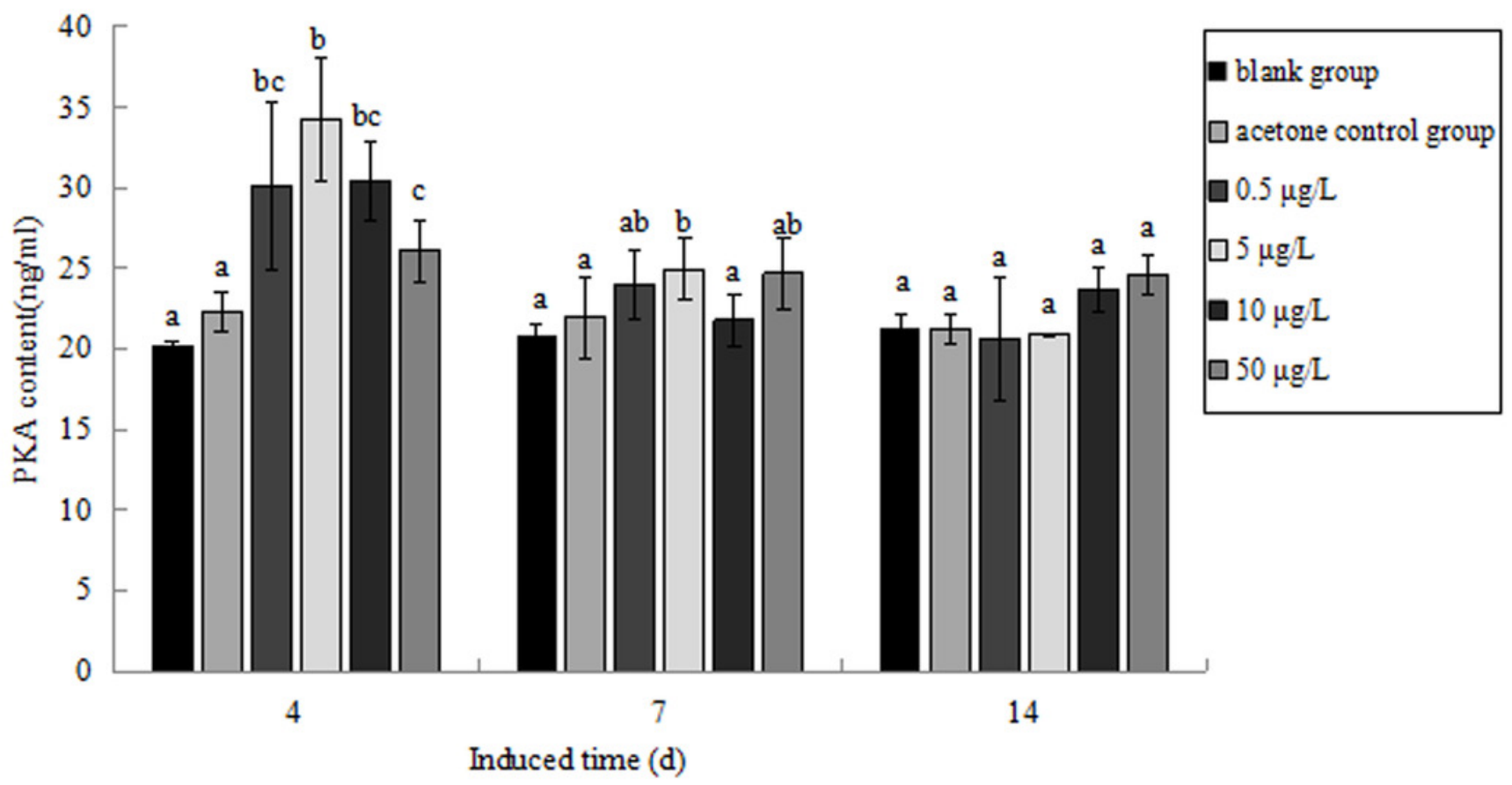


Table $\mathbf{1}$ (on next page)

The primers used in this study 


\begin{tabular}{|c|c|c|}
\hline \multicolumn{2}{|c|}{ Primer name } & \multirow{2}{*}{$\frac{\text { sequence }\left(5^{\prime}-3^{\prime}\right)}{\text { TGAGAAACGTCGAAGCGAAAGG }}$} \\
\hline RACE & GPCR - F1 & \\
\hline & GPCR - R1 & ATATTCGACGCTGACCCTAAGG \\
\hline & PKA-F1 & GATACCCACCTTTCTTTGCTGACC \\
\hline & PKA-F2 & GGTGCGCTTCCCATCTCACTTT \\
\hline & PKA-R1 & CAATAGCGCAGCCTCAGGGACA \\
\hline & UPM Long & CTAATACGACTCACTATAGGGCAAGCAG \\
\hline & & TGGTATCAACGCAGAGT \\
\hline & UPM Short & CTAATACGACTCACTATAGGGC \\
\hline \multirow[t]{6}{*}{ Real time PCR } & $\beta$-actin-R & CGAAGTCCAGAGCAACATAG \\
\hline & $\beta$-actin-F & GGGCTACTCCTTCACCACCA \\
\hline & GPCR-R3 & CCGTAAAAGCCTCATCAAGACA \\
\hline & GPCR-F3 & TTGGCAGGTGTAAATGAATGG \\
\hline & PKA-F3 & GACCAGCCAATCCAAATCTATG \\
\hline & PKA-R3 & GACCCCATTCTTCAGGTTTCC \\
\hline
\end{tabular}

1

2

3

4 